\title{
In-situ X-ray tomography of wear - a feasibility study
}

\author{
Jure Aleksejev $^{\mathrm{a} 1}$, Yijun Lim ${ }^{\mathrm{b}}$, John Huber ${ }^{\mathrm{a}}$, Felix Hofmann, James Marrow ${ }^{\mathrm{b}}$ \\ ${ }^{a}$ Department of Engineering Science, University of Oxford, Parks Road, Oxford, OX1 3PJ \\ ${ }^{b}$ Department of Materials, University of Oxford, Parks Road, Oxford, OX1 3PH
}

\begin{abstract}
Wear experiments using annular contacts were carried out to investigate the possibility of imaging wear scars and wear debris beds in-situ. Samples made of $6082 \mathrm{~T} 6$ aluminium alloy were subjected to unidirectional wear under different conditions with the sample elements then locked in contact to preserve the end-of-wear condition. Post-wear 3D morphology was successfully imaged in-situ using $\mathrm{X}$-ray tomography, with total depth of the wear scar, surface primary-profile roughness and real area of contact also obtained. This study is a proof-of-concept illustrating the utility of tomography for studying wear, without the need to disassemble the contact or disturb the debris bed and serves as a starting point for a new approach to the investigation of wear phenomena.
\end{abstract}

\section{KEYWORDS}

X-ray tomography, Wear, Debris bed, Real area of contact

\section{INTRODUCTION}

Despite decades of intense study of wear $[1,2]$, researchers still face substantial limitations when observing wear processes due to the inaccessible nature of the wearing contact. Post-mortem and exsitu examination of wear samples through profilometry, microscopy, metallography and other techniques is an established approach [3] but such techniques can only reveal the end state of the wear process and typically disturb the worn contact. Establishing the dynamics of wear then requires repeated experiments with the wear process interrupted at different stages, which is time-consuming, costly and presents issues of repeatability. Real-time observations of wear and other tribological phenomena are possible with use of transparent counter-bodies [4, 5, 6, 7]. This, however, introduces new variables associated with the material of the counter-body and inevitably changes the nature of the contact. A technique enabling the contact area, its worn profile and any accumulation of wear debris to be examined in-situ would be of great use to the field of tribology, as it eliminates the need for optically transparent bodies or breaking the contact.

$\mathrm{X}$-ray imaging methods provide a potential solution to this problem by enabling non-destructive measurement with fine resolution. Between 1997 and 2000 several papers have emerged from Nanyang Technological University describing the use of X-ray microscopy to investigate the wear scars and wear debris beds in situ $[8,9,10]$, demonstrating that wear of metals can be imaged in two dimensions using penetrating radiation. Unfortunately this body of work appears to be little known to tribologists of today. Using a geometrically similar setup, Belin et al. [11] used X-ray transmission through a microscopic

\footnotetext{
${ }^{1}$ Corresponding Author. Email: jure.aleksejev@chch.ox.ac.uk
} 
contact as a measure of the progression of wear. Recently, Dorgham et al. [12] used in-situ X-ray absorption spectroscopy to study lubricant films.

Over the past twenty years, different branches of tribology made extensive use of X-ray computed tomography. Accurate ex-situ measurements of 3D worn profiles (and therefore indirectly wear volume) have been demonstrated by Zanini et al. [13], Affatato et al. [14] and Hejjaji et al. [15], essentially using X-ray CT as a substitute for more traditional profilometry methods. In combination with particle tracking, X-ray tomography has been used to observe and study Couette flow of granular materials [16] in-situ. Several ex-situ CT studies of wear and/or rolling fatigue cracks are reported [17, 18, 19, 20, 21]; in-situ investigations of tribo-fatigue-induced cracking in metals have also been performed successfully [22, 23, 24], enabling the growth of fatigue cracks to be visualized. X-ray tomography has also been used to study frictional welding: Steuwer et al. [25] studied the morphology of weld inclusions resulting from wear of friction stir welding tools, while Cornuault \& Carpentier [26] obtained post-weld tomographs of the welded zone in linear friction welds. In the work of Mandard et al. [27], X-ray tomography was used to observe the change in porosity of abradable porous layers caused by sliding wear and also to observe the morphology of individual wear debris particles. However, this was done ex-situ and no attempt was made to image the wearing bodies in contact or observe the particles before they were ejected from the debris bed.

These studies demonstrate the ability of X-ray methods to resolve a number of tribological features on micrometre and nanometre scales, but there has been little attempt to image the wear-zone in more than just straight-forward 2D transmission or quantify wear-related phenomena (debris bed thickness, wear scar profile, debris particle shapes etc.) through the use of X-ray imaging without breaking the contact of the wearing bodies.

In wear of metals, the worn surfaces are typically much rougher than the virgin surface. Wear also generates debris particles of size in the range tens to hundreds of micrometres and these particles may be oxidized [28, 29], providing X-ray contrast. Hence, X-ray tomography should provide a capability to resolve both wear surface features and wear debris, enabling the worn contact to be imaged in-situ. Modelling of wear has been used to investigate the dynamics of the wear process and recent work supports the view that a realistic wear model must account for the presence and properties of the wear debris layer [30, 31, 32, 33]. X-ray methods provide an opportunity to generate the observations concerning the development of the wear scar and the properties of the wear debris (debris bed thickness, debris particle size and size distribution), which are of crucial importance for testing and further development of wear models. As most wear studies only present the end state of the wear process, there is a dearth of evidence comparing experimental measurements of these parameters with model-based predictions of wear process development.

In this report, we present a proof-of-concept demonstration of applying X-ray tomography to the investigation of wear. The intention is to explore the capabilities of a novel investigative technique, rather than to produce a detailed study of a particular wear process. Thus, the wear geometry, material and wear conditions were selected in accordance with what was simple and technically feasible to realize with time and resources available, rather than with the intention of simulating a specific real wearing contact. We show that the total depth of wear scar, the surface roughness and the real area of contact are readily measured; we also compare X-ray observations with conventional techniques such as metallography and optical profilometry. This demonstrates that X-ray tomography provides a powerful approach to studies of wear with significant potential for future development. 
A widely used aluminium alloy (6082T6) was chosen as the sample material, as its low-density gives greater X-ray transmission and therefore lower imaging time. Cylindrical sample elements with an annular contact region were used (Figure 1A). The wearing contact geometry was a contact of two annuli, each having an external diameter of $4 \mathrm{~mm}$ and internal diameter $2 \mathrm{~mm}$, as this was judged to be the geometry best suited to imaging (as it is rotationally symmetric) and the largest size that could be imaged in reasonable time. Recently, annular geometry has been subject of increased interest in wear studies due to its unique properties compared to more common incomplete contacts [34, 35, 36, 37].

Wear sample elements were mounted onto sample holders, and fixed into a rotary wear machine. A tubular plastic clamp was positioned onto one of the sample holders for later use. A constant normal force was applied along the sample axis while one sample element was rotated unidirectionally against the other at a speed of $40 \mathrm{rpm}$ (the slowest rotational speed available on the machine). The non-rotating sample element was fed axially to maintain the contact load as wear proceeded. After the determined period of rotation had finished, the plastic clamping tube was slid over the sample pair (Figure 1B) and tightened with clips, locking the sample elements together. This preserved the contact condition of the worn sample during transfer from the wear apparatus to the tomography system. The normal load was then released and the sample holders detached. The tubular clamp is estimated to retain about $25 \%$ of the normal force applied during testing. The clamped sample was imaged using an Xradia Versa 510 micro CT system (Zeiss, Germany) using a voxel size of $2.47 \mu \mathrm{m}$, tube voltage of $100 \mathrm{kV}$ (tungsten target) and exposure time of 8 seconds per projection. Total exposure time was 8 hours, with the output volume occupying approximately 2000x2000x2000 voxels. Further image processing and 3D rendering was performed using Aviso 9.7.0 (ThermoScientific, USA) and FIJI [38] image processing software.

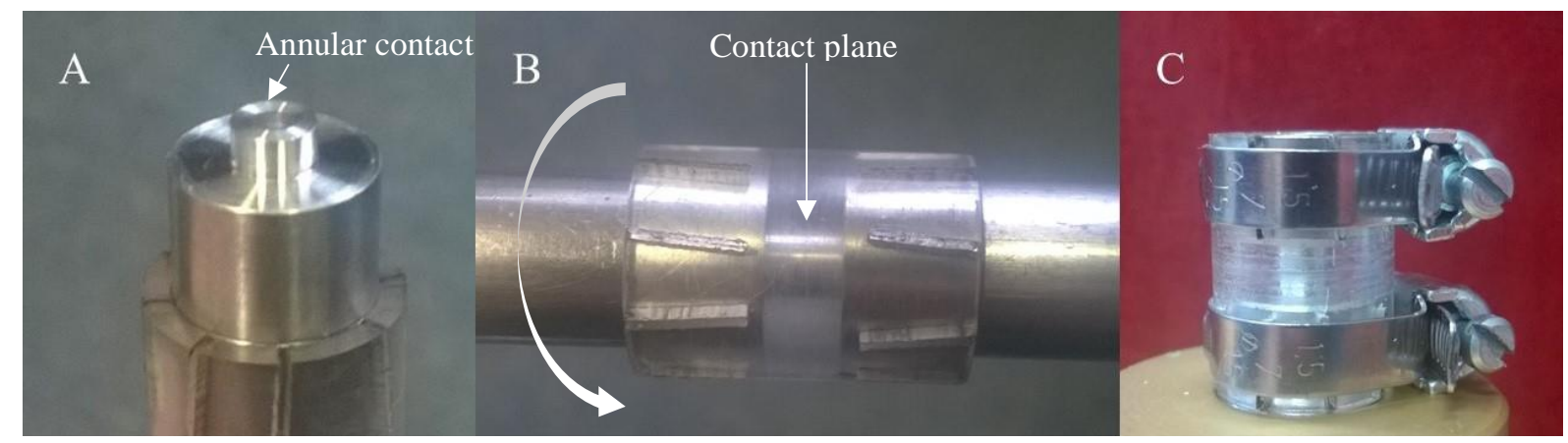

Figure 1: The wear sample. (A) Unworn sample element showing the annular contact surface (B) Sample elements mounted in contact, with the clamp in position, but without clips. The direction of rotation is shown. $(C)$ The fully clamped sample after wear and tomography.

In total, five experiments were conducted, one for each set of parameters shown in Table 1. The experimental parameters provide variation of normal load, and distance slid (distance calculated at the mid radius of the contact) which are two key parameters believed to influence wear in accordance with Archard's law [39]. The expectation was that these parameters may influence the morphology of the worn region.

\begin{tabular}{lll}
\hline Axial force $(\mathrm{N})$ & Sliding time $(\mathrm{s})$ & Total distance slid $(\mathrm{mm})$ \\
\hline 45 & 300 & 1884 \\
45 & 900 & 5652 \\
130 & 60 & 377 \\
130 & 300 & 1884 \\
130 & 900 & 5652 \\
\hline
\end{tabular}

Table 1: Experimental parameters 


\section{RESULTS}

Using Avizo software, a 3D representation of the worn contact can be made, as seen in Figure 2. The resolution of the tomograph is sufficient to show the extensive burring and scuffing, as well as particulate matter attached to the surfaces. The 3D render provides an overview of the exterior of the worn sample. However the underlying data-set is a complete spatial representation of the sampled region; with suitable processing it can yield in-depth insight into the post-wear morphology. We illustrate this by using axial slices to study the wear scar and debris bed, radial slices to study the worn surface profiles, and volume analysis to estimate true contact area.

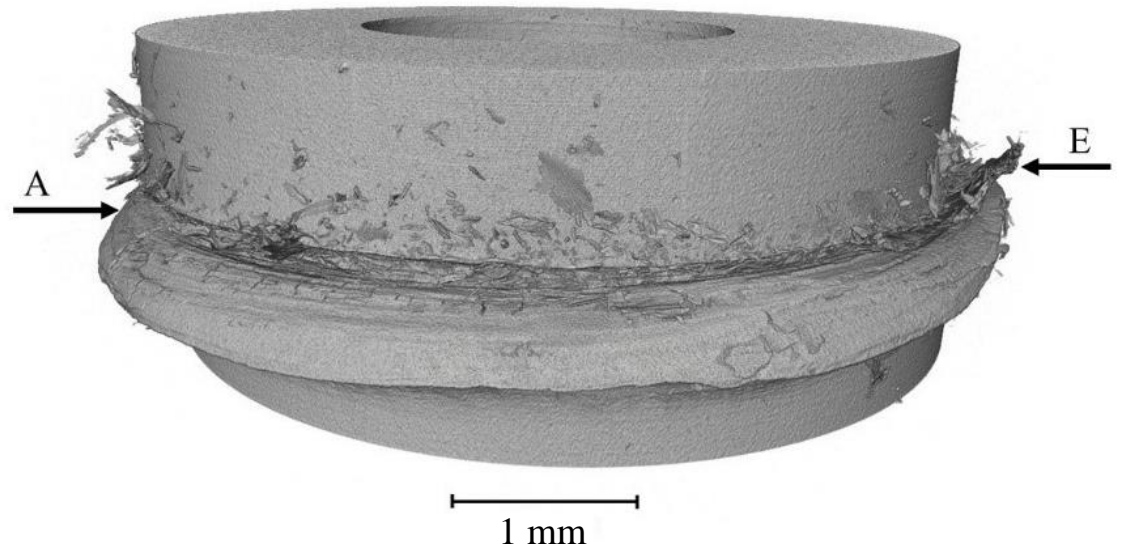

Figure 2: $3 D$ render of the worn sample (axial height approximately 560 slices or $1.38 \mathrm{~mm}$ ). Normal force: $130 \mathrm{~N}$, sliding time: $300 \mathrm{~s}$. A and E mark the positions of two axial slices, which are $300 \mu \mathrm{m}$ apart.

\subsection{Axial slices and the wear scar}

Axial cross-sections reveal the shape of the wear scar and the wear debris particles entrapped. In Figure 3 , an axial slice is superimposed on the 3D render of the worn region, which has been made translucent in order to show the relationship between the axial slice and the sample geometry. Figure 4 shows series of such axial slices; the positions of slices A and E relative to the sample are marked in Figure 2. Axial slice A is taken just below the wear scar and clearly shows the local increase in diameter due to plastic deformation near the contact, despite the nominal contact pressure being below $10 \%$ of the yield stress of the 6082T6 alloy. Separate tests using reciprocating annular contacts have indicated that the extent of plastic deformation is strongly dependent on the accumulated sliding distance and displacement amplitude. Tomography could be used to monitor the development of this plastic deformation with the progress of wear. Also visible in slice A are small cracks developing in the plastically deformed fringes of the sample. Slices B-D are taken from close to the centre of the worn region and show deep pits in the worn surface, which appear across many slices. Also visible are wear debris particles that are trapped in the wear scar. In principle, with sufficient resolution, debris particle size and distribution could be estimated, however, this requires a full consideration of the 3D data set that has not been attempted here. Slice E is taken from above the wear scar, where the slice geometry is almost unaffected by wear. Thin slivers of material can be seen outside the main body of the sample; these appear to be the edges of thin burrs connected to the sample. A series of axial cross-sections can also be joined into a video showing the debris bed from the perspective of an observer moving along the central axis of the contact. Two examples (samples worn at 45 and $130 \mathrm{~N}$ for $900 \mathrm{~s}$ ) are provided in the online supplementary materials. 


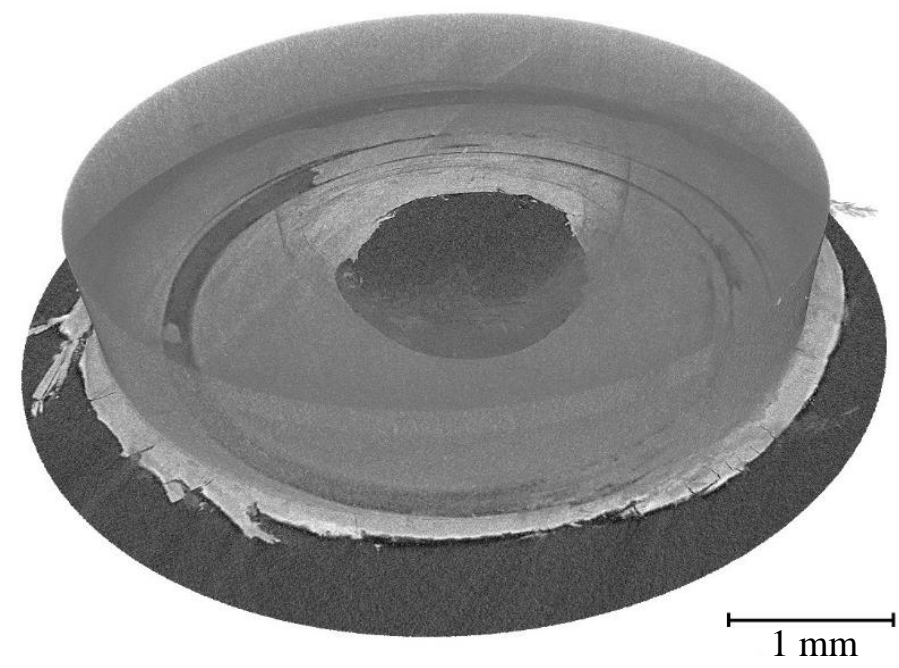

Figure 3: Axial cross-section in Avizo. Normal force: $130 \mathrm{~N}$, sliding time: $300 \mathrm{~s}$, sample elements made translucent for clarity.

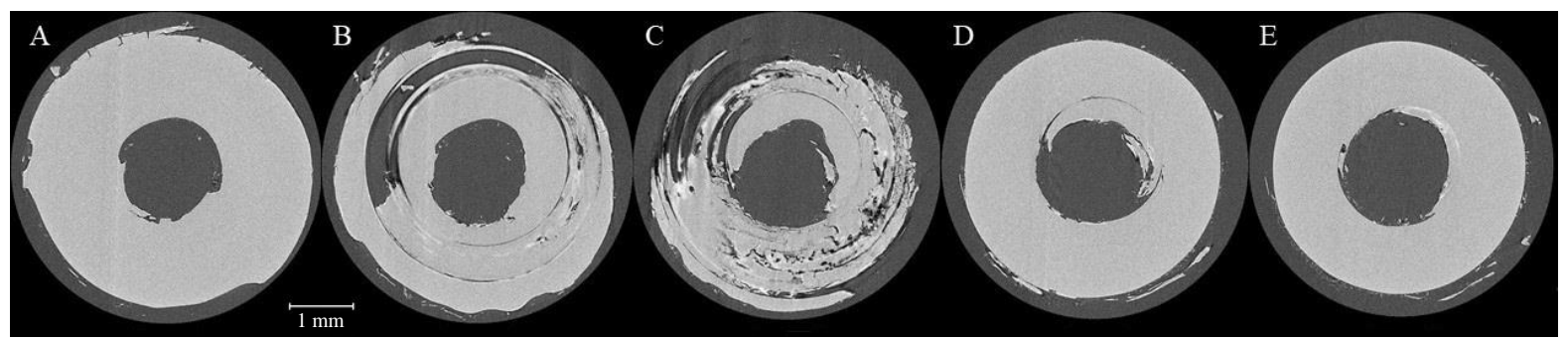

Figure 4: Axial cross-sections through the worn region; sections A and E correspond to positions shown in Figure 2. Lighter areas represent metal, darker areas air. Axial distance between sequential slices is $74 \mu \mathrm{m}$. Normal force $130 \mathrm{~N}$, sliding time $300 \mathrm{~s}$.

By examining each axial slice, the uppermost and lowermost point at which mechanical damage to the surface of each sample element appears, can be determined. The axial distance between these two slices defines a total depth of wear scar, that is, the axial distance between the bottoms of the deepest surface pits on either of the contact surfaces. Total depth of the wear scar is therefore the property of the worn pair as a unit and depends on the size of surface asperities, the relative rotational position of the sample elements and the debris accumulation. The total wear scar depths measured in this way are shown as a function of normal force and sliding distance in Figure 5. The total depth of the wear scar represents an upper bound on the debris bed thickness. Locally, the debris bed thickness can vary from zero (first body contact) up to the total depth of the wear scar. The wear debris bed thickness is of great significance in certain models of wear [40, 41], however, measuring the debris bed thickness without interrupting the wear process remains challenging with traditional techniques. Tomography may provide a route to assessing debris bed thickness in-situ. In Figure 5, a generally increasing trend of wear scar depth with distance slid can be seen; somewhat unexpectedly lower normal load also led to a much larger total wear scar depth in one case, however, as we have only collected limited data we do not speculate as to a specific relationship. 


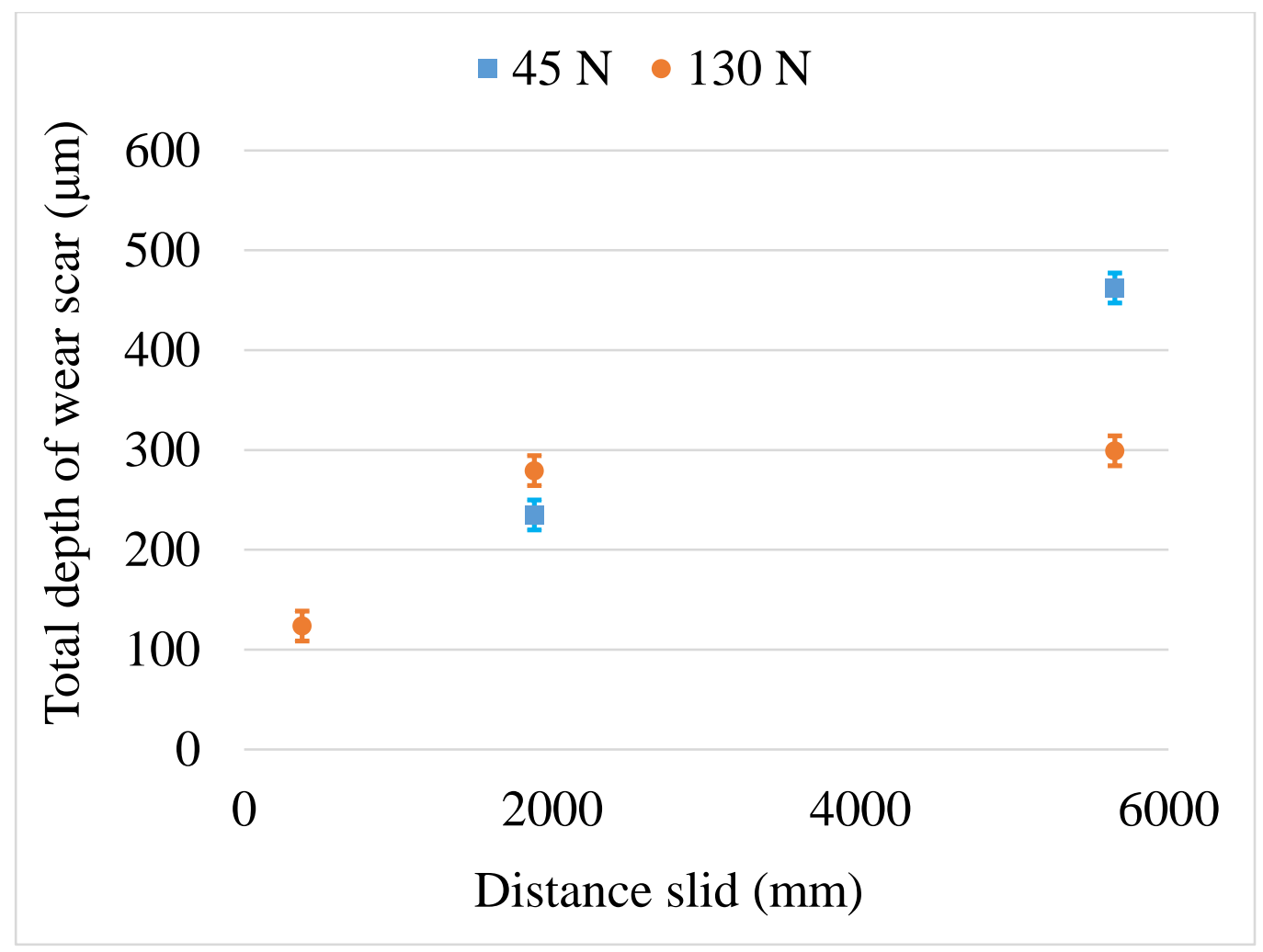

Figure 5: Total depth of wear scar as a function of normal force and sliding distance. Error bars show the absolute error of measurement.

\subsection{Radial slices and radial surface profiles}

Figure 6 shows a radial slice through the worn region superimposed on the 3D render of the sample. Radial slices can be made in any number and in any orientation, revealing the material entrapped between the surfaces of the first bodies and severe roughening of the surfaces. Figure 7 shows a typical radial slice and also the lines representing the total depth of the wear scar on that slice, to help visualized the concept referred to in section 3.1.

An advantage in comparison to conventional metallography is that every part of the sample can be viewed without damage to the debris bed or the sample. To give a direct comparison between tomography and metallography, a sample element (worn at normal force of $130 \mathrm{~N}$ for $900 \mathrm{~s}$ ) was sliced using a diamond saw, mounted in resin and wet ground with abrasive papers up to 2500 grit. Figure 8 shows the optical metallographs obtained alongside a corresponding tomography slice from the same sample, displaying excellent agreement between the two. 


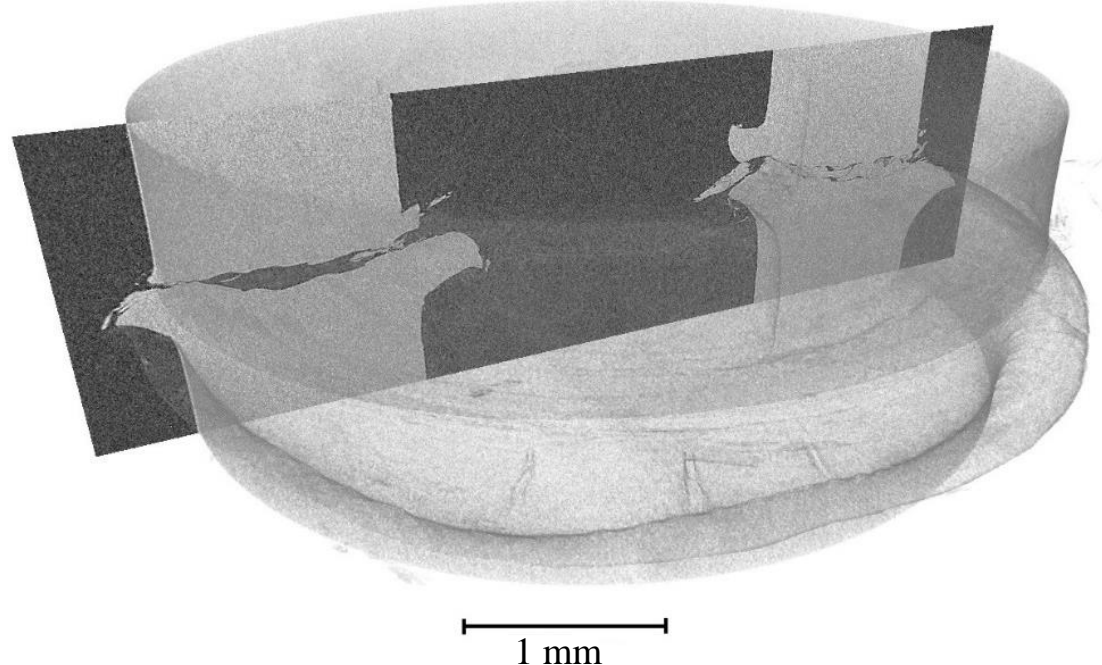

Figure 6: Radial cross-section in Avizo. Normal force: 130 N, sliding time: 300 s. Sample elements made translucent for clarity.

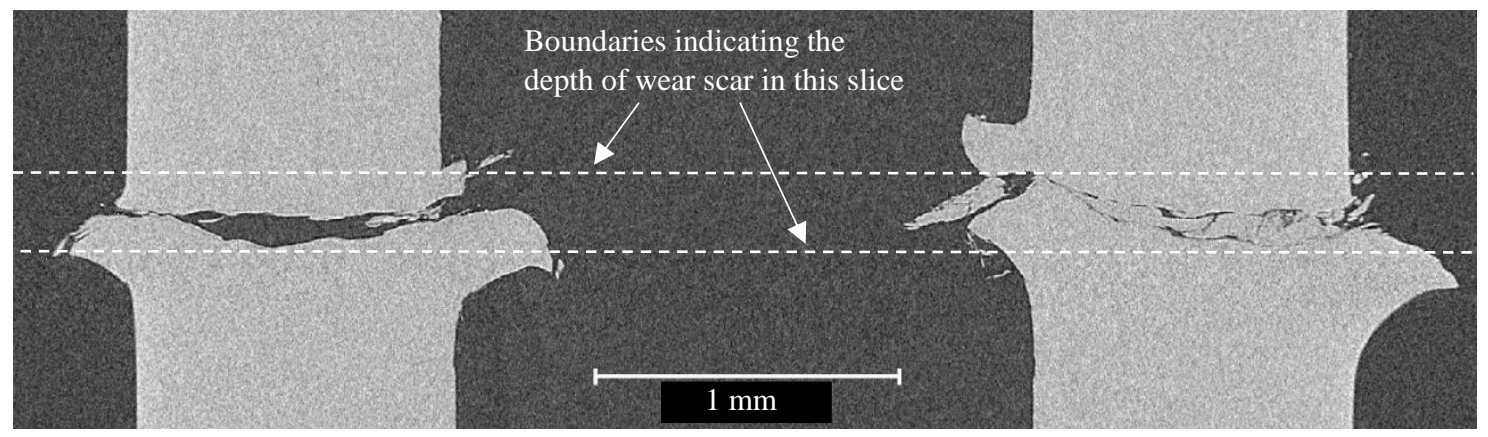

Figure 7: Radial cross-section of the worn annulus. Normal force $130 \mathrm{~N}$, sliding time 300 s. Depth of the wear scar shown is less than the total wear scar depth, which is the difference between the highest and lowest point in the entire contact.

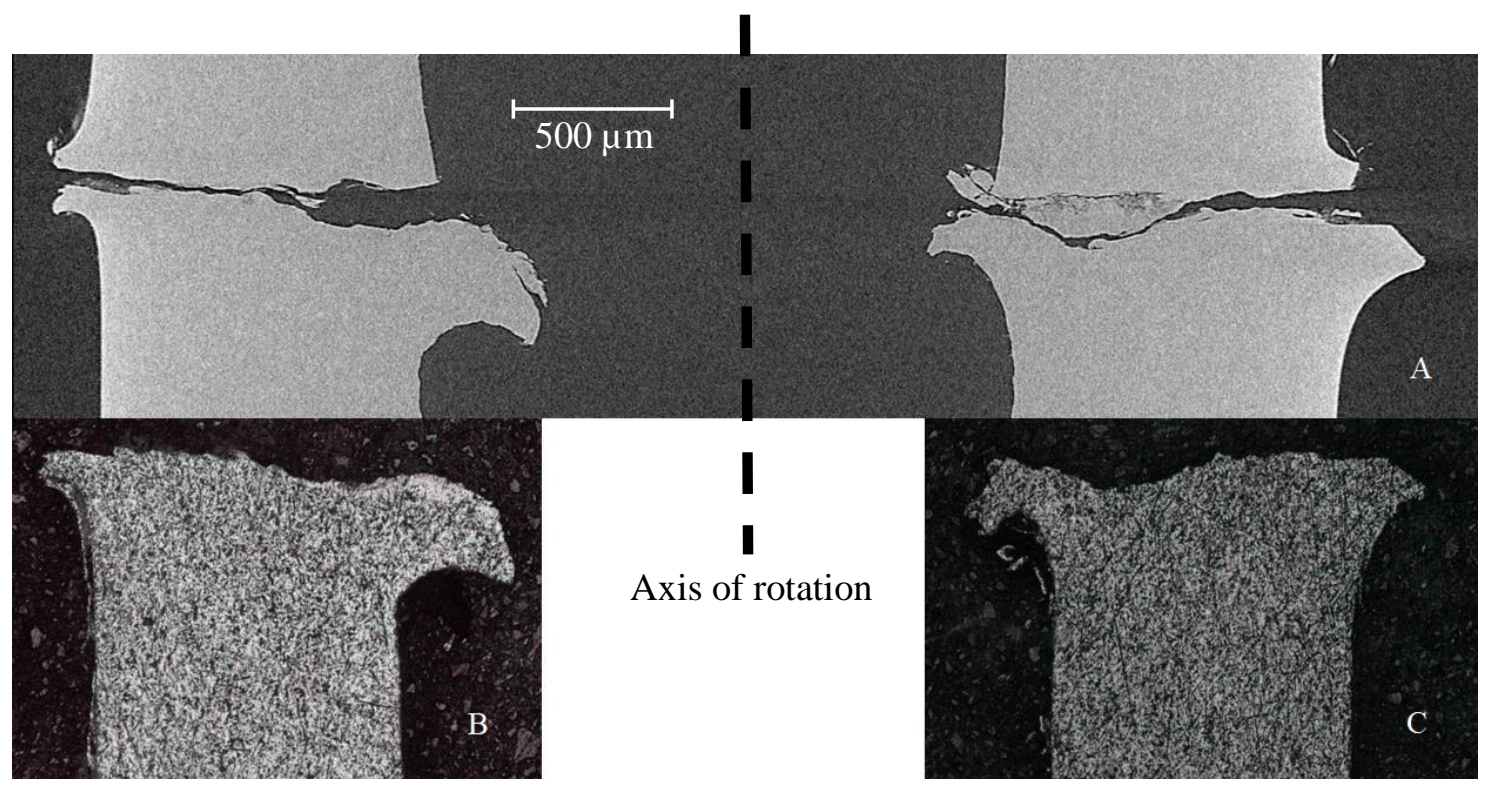

Figure 8: Section comparison. Radial tomography slice (A). Optical metallographs of the same sample element (B, C). Normal force $130 \mathrm{~N}$, sliding time $900 \mathrm{~s}$. 
From radial cross-sections, the primary surface profiles in the radial direction can be extracted, by tracing the outline of the metal region, extracting the trace as a coordinate set and trimming the set to only the contact surface. The resulting coordinate set was used to estimate the post-wear primary profile roughness. For each roughness estimate, several profiles were used and an average of their roughness values was computed. To compare the results with a conventional technique, two samples were disassembled and the sample elements scanned on an optical profilometer (InfiniteFocus, Alicona, Austria), taking eight radial profiles in arbitrary positions on the relevant surfaces, and the individual values averaged. Figure 9 shows the roughness values measured for tests using normal force of $45 \mathrm{~N}$ and a comparison with the Alicona data. This shows excellent agreement between the two measurement methods, indicating that tomography could provide reliable roughness data in-situ. Figure 10 provides similar results for the tests using normal force of $130 \mathrm{~N}$, however agreement with the Alicona is less good in this case. Only $R_{a}$ roughness values are shown for brevity, although other measures $\left(R_{q}, R_{z}\right)$ can be readily obtained. The 'lower' and 'upper' labels in Figures 9 and 10 refer to the position of the worn surfaces with respect to the Xradia machine. Based on this limited data set, it appears that the roughness tends to increase with distance slid, and hence, the development of the wear process. In contrast, changing the applied load did not greatly affect the surface roughness.

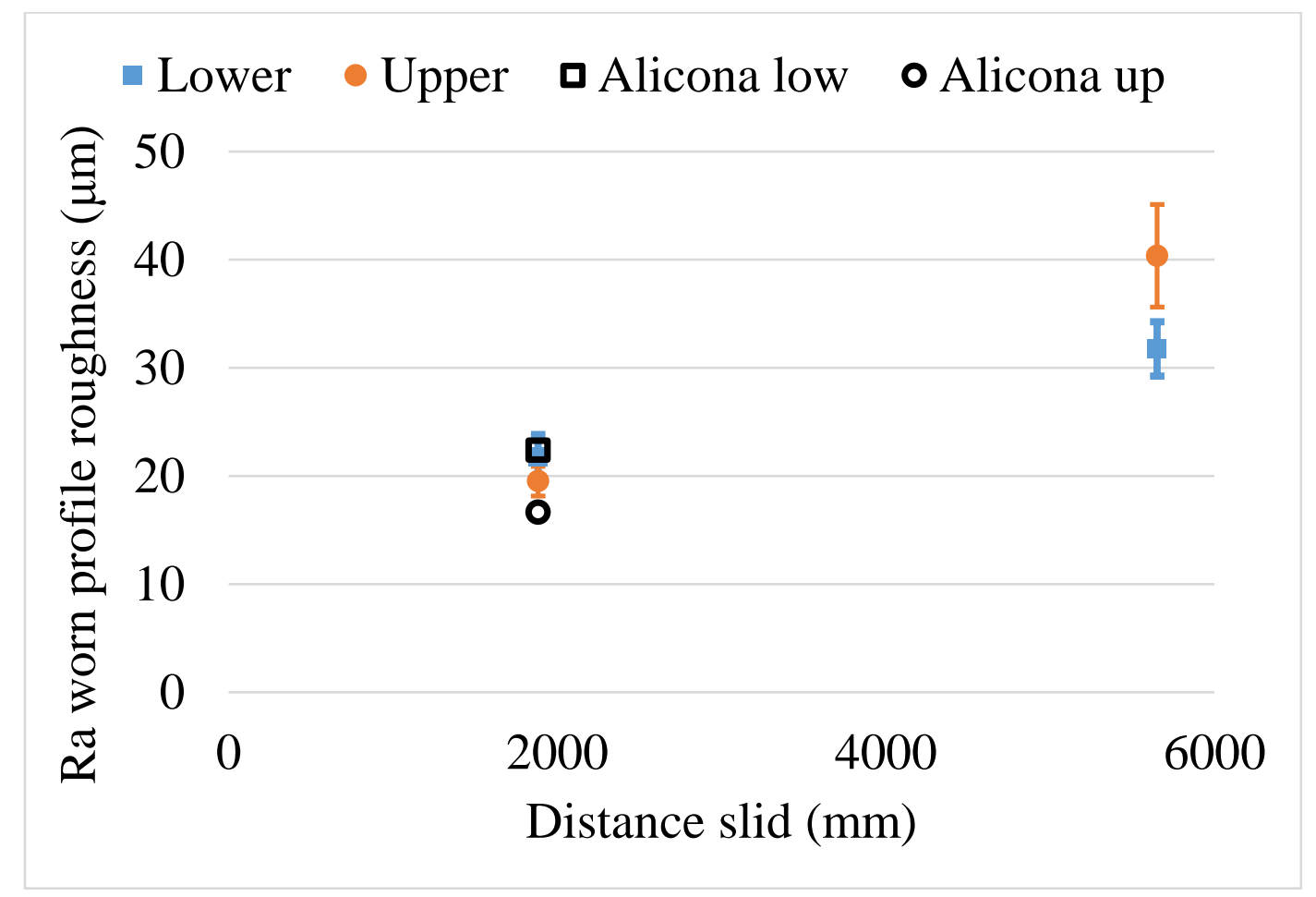

Figure 9: Worn Ra primary profile roughness obtained at normal force of $45 \mathrm{~N}$. Error bars show standard error. 


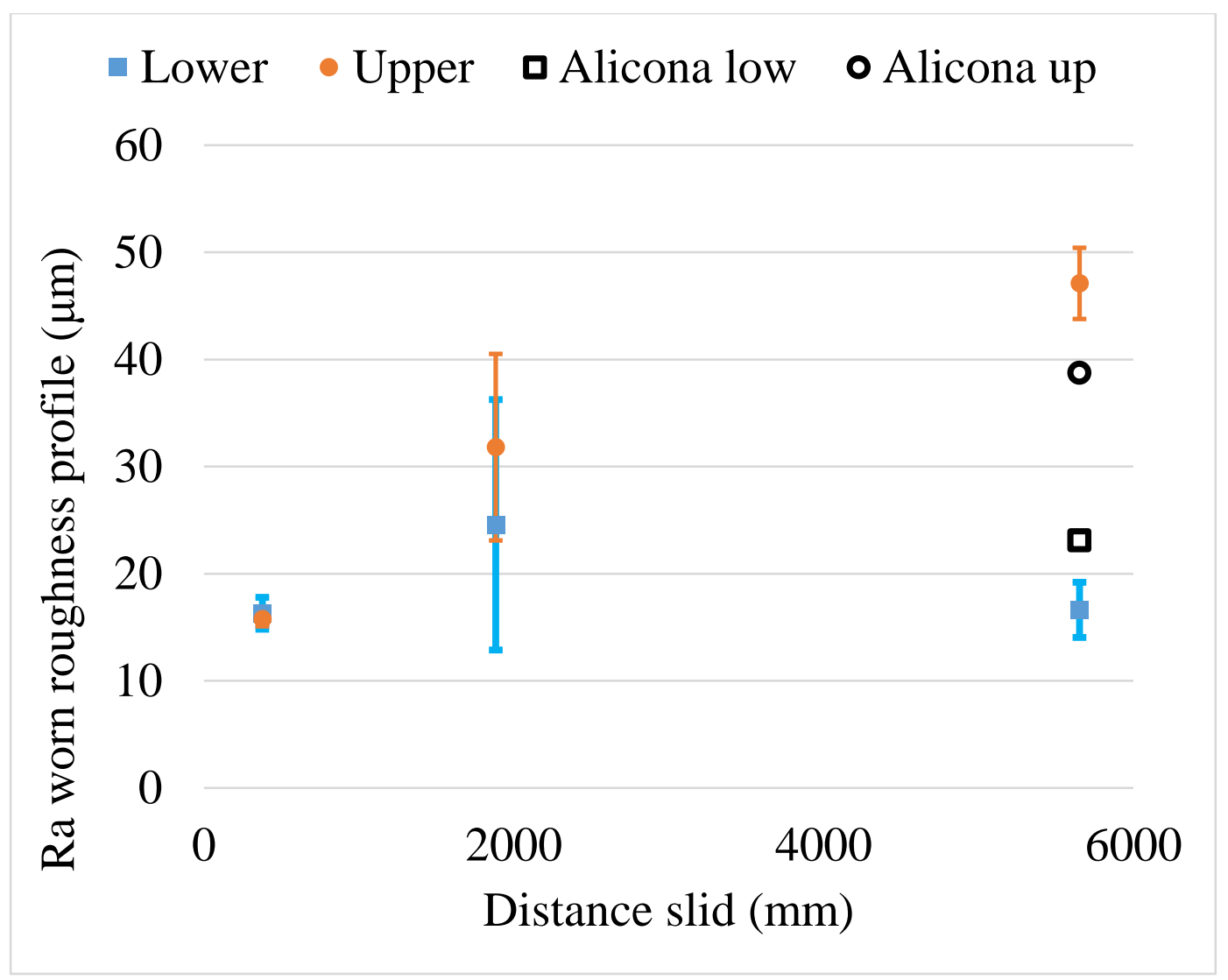

Figure 10: Worn Ra surface roughness obtained at normal force of $130 \mathrm{~N}$. Error bars show standard error.

\subsection{Real area of contact}

The real area of contact is of importance in wear as the location of greatest local stresses and heat generation [42, 43, 44, 45]. In electrical contacts, the real area is of importance to contact resistance $[46,47]$. To assess the real area of contact, the tomography data-set was segmented using X-ray absorption contrast into a metallic region and an air region. Views of the shape of the air-filled region are shown in Figure 11A, B. To understand these images, note that they are prepared by the same process as Figure 2, except that in Figure 2 the metallic region was retained and the air region removed. A number of irregular-shaped openings in the air region may be observed in Figure 11B; these represent continuity of the metal in the axial direction, caused by points of contact between the sample elements. After thresholding using FIJI (Figure 11C), the combined area represented by these openings was computed. This provides an estimate of the real area of contact. The ability to observe real area of contact between worn metallic surfaces using 2D x-ray imaging has been demonstrated by Fu et al [9], but they did not attempt to measure it. Recently, an experimental approach similar to the one described above was used by Zhang et al. [48] to measure the real area of contact between artificially textured surfaces, obtaining good agreement with the finite element simulation of the surface geometries studied. 
Note, however, that the limited resolution of the tomograph prevents accurate interpretation of features smaller than approximately $2 \mu \mathrm{m}$. Since the limit of resolution could cause either thin air gaps or sufficiently small points of contact to be misinterpreted, the computed area of contact could be either an underestimate or an overestimate. Contact regions smaller than $2 \mu \mathrm{m}$, yet spanning the typical wear scar depth seem relatively unlikely given an $\mathrm{R}_{\mathrm{a}}$ surface roughness of tens of microns. In contrast, air gaps of thickness less than $2 \mu \mathrm{m}$ are more likely to occur because any gap located close to a contact region is likely to be thin. This positive contribution increases with the length of the contact area boundary. Given this, the resolution-related inaccuracies are likely to increase the apparent size of the contact area. In addition, cases where a surface asperity is so shaped, that the contact with the opposite surface lies outside the base of the asperity would not be identified by this process, and similarly with certain convoluted surface geometries. The contribution of this effect to the total inaccuracy cannot be established conclusively, however we would expect that repeating the imaging at several different resolutions would result in the real area of contact observed showing an asymptotic trend, giving an indication of what the true value might be. Despite such limitations, X-ray tomography appears to be the only reliable method for directly estimating the real area of contact between rough/worn metallic bodies currently developed. Although a variety of computational methods for predicting contact area has been proposed $[49,50,51]$, they require experimental validation and quantitative area measurements to verify their accuracy. This is reasonably straightforward for cases where the surface texture is known and the surfaces otherwise clean, but difficult in the presence of wear debris and without detailed knowledge of surface topography.

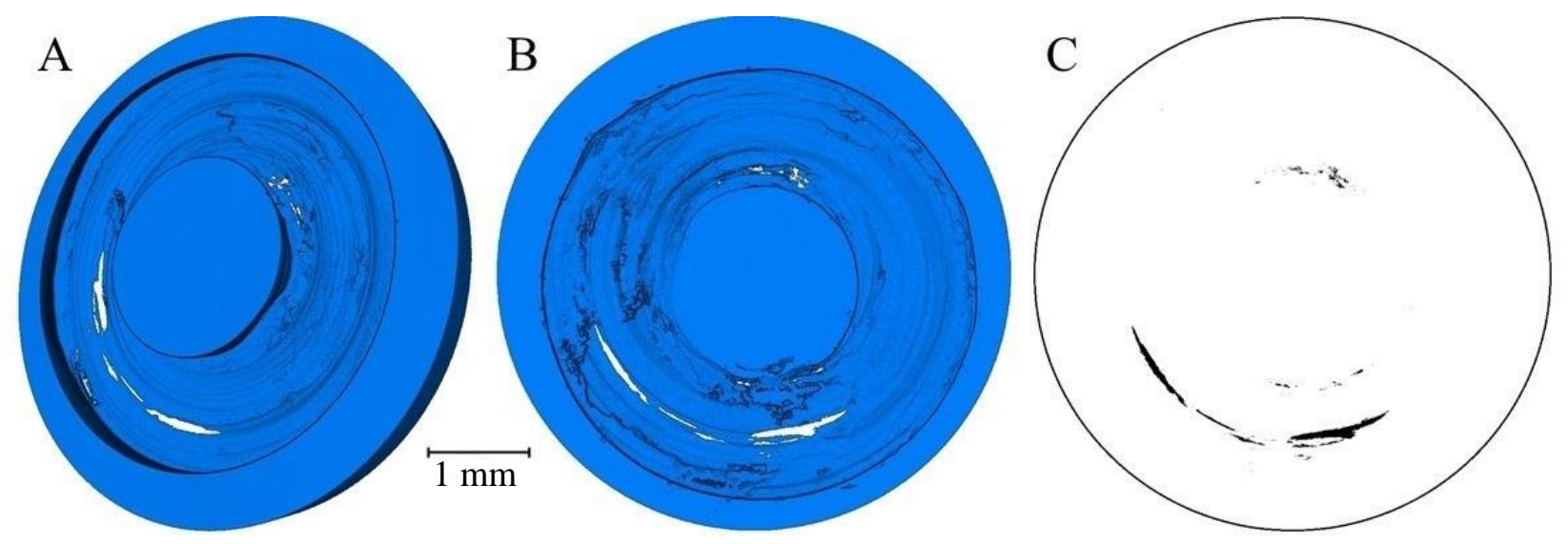

Figure 11: Views of the air region (A) 3D render of the air-region showing its general shape. (B) Axial view of the air region; white areas correspond to axial holes in the air region. (C) Post-processed image showing locations of direct contact between metallic surfaces; the circle represent the external diameter of the air region. Normal force $45 \mathrm{~N}$, sliding time $300 \mathrm{~s}$ 


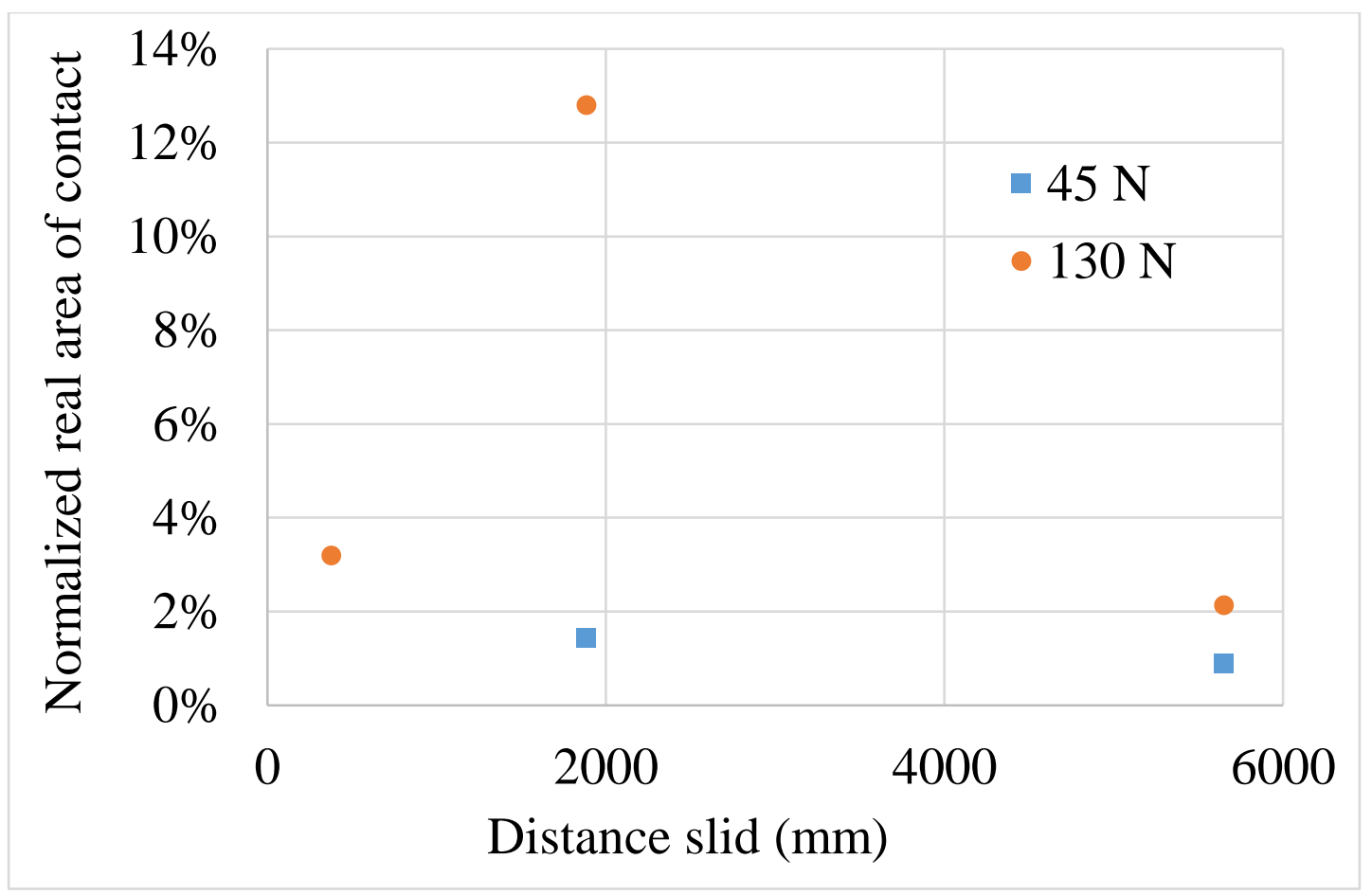

Figure 12: Normalized real area of contact as a function of normal force and sliding distance.

The real contact area estimates (normalized with respect to the nominal contact area) are shown in Figure 12. In most cases, the real contact area is less than $4 \%$ of the nominal area and the distribution shown in Figure 11 is typical in that the majority of the real contact area is located in a crescent shaped cluster of patches. We note that increasing the load increases the measured contact area, though with limited data there is no observable trend in contact area versus accumulated sliding distance. The results obtained are in line with the widely held expectation of the real area of contact being small compared to the nominal area.

\section{CONCLUSIONS}

The purpose of this work was to investigate and demonstrate the ability to collect observations of wear of metallic components without disturbing the wearing contact. This was successfully accomplished using X-ray tomography and the resulting data-set was shown to provide measurements of total wear scar depth, surface profile, roughness, and real area of contact. Despite the evident advantages of X-ray tomography in this application and extensive survey of available literature, no previous studies of this type were identified.

It was demonstrated that the profile and roughness measurements were consistent with conventional post-mortem examination techniques. In addition, data that are not obtainable through other methods were collected; in particular, the total depth of the wear scar was assessed. We expect that it will be possible to measure the wear debris bed thickness using a similar approach; this is of importance to multi-body models of wear. By measuring the growth of the wear debris bed and observing the behaviour of wear particles under different conditions it would be possible to test mathematical models of debris bed development and study the effects of wear conditions on bed behaviour in greater depth. Measuring the total depth of the wear scar during wear is challenging with traditional techniques but readily accessible by $\mathrm{X}$-ray tomography. 
While the use of radiography and X-ray computed tomography for observing and measuring the real area of contact between rough metal surfaces has been proposed independently, this work appears to be the first to quantify the real area of contact between surfaces roughened by wear using this approach. Establishing what the real area of contact is, how it changes with wear and how it varies through the wear cycle is of interest in studies of electrical and heat conductivity through the contact. In principle, observing the real area of contact also has applications in studies of lubrication, since the transitions between lubrication regimes are defined in terms of the area of contact between the lubricated surfaces. However, even with a very bright X-ray source such as a synchrotron the imaging times needed for a full tomography are estimated to be of several minutes, which is impractical for such an application. For the same reason, it is unlikely that a single cavitation event in lubricant film between metal surfaces could be observed, but time-averaged distributions of vapour fractions in macroscopic cavitating flows have been collected successfully $[52,53,54]$ using x-ray computed tomography. As demonstrated by previous work [24, 20, 17, 22, 23], x-ray tomography is capable of resolving subsurface cracks. Use of $\mathrm{x}$-ray tomography in wear studies can therefore be extended to observe not only the development of the contact region, but also the material around it, which could be beneficial in studies of wear-induced cracking. In principle it could also be possible to observe the separation of an individual debris particle through delamination, but this was not attempted here, as that would demand the wear zone on the same sample to be imaged repeatedly during the wear process.

In the present study, the process of wear was separated from the imaging process. However, with appropriate equipment, the sample can be repeatedly imaged during the wear process, enabling observation of the progression on a single sample. A larger-scale in-situ wear experiment using synchrotron radiation is currently under development, aiming to simultaneously decrease the imaging time and apply X-ray diffraction in conjunction with tomography to study wear-induced changes of the microstructure. We expect to be able to collect numerous tomographs and diffraction scans per sample at different stages of the wear process to observe the development of surface roughness, the growth of the wear debris bed, changes in real area of contact, growth of subsurface cracks, as well as plastic deformation/recrystallisation of the material under the wear surface.

\section{ACKNOWLEDGMENTS}

The authors wish to thank Yang Chen for his extensive help with Avizo software, image processing and related advice. Thanks are also due to Marzena Tkaczyk and the Oxford University workshops who provided practical support, and Prof. David Hills who proposed the study of annular contacts. This work was supported through Rolls Royce Plc contract number 4800000925 and the Cornerstone prosperity partnership. Felix Hofmann acknowledges funding from the European Research Council (ERC) under the European Union's Horizon 2020 research and innovation programme (grant agreement No 714697). Xradia and Avizo facilities were funded through the EPSRC Grant EP/M02833X/1 "University of Oxford: experimental equipment upgrade".

\section{REFERENCES}

[1] P. Blau, "Fifty years of research on the wear of metals," Tribology International, vol. 30, pp. 321-331, 1997.

[2] K. Budinski, Friction, wear, and erosion atlas, Boca Raton: CRC Press, 2013.

[3] G. Stachowiak, A. Batchelor and G. Stachowiak, Experimental Methods in Tribology, 1. ed., vol. 44, Elsevier Science, 2004. 
[4] B. Briscoe, A.Chateauminois, T. Lindley and D. Parsonag, "Fretting wear behaviour of polymethylmethacrylate under linear motions and torsional contact conditions," Tribology International, vol. 31, pp. 701-711, 1998.

[5] C. Feng, D. Zhang, K. Chen, Y. Guo and T. Hao, "Research on in-situ microscopic observation of dynamic contact and reciprocating sliding friction of GM-3 lining interface," Tribology International, vol. 115, pp. 179-190, 2017.

[6] R. Charlery, M. Renouf, A. Saulot, N. Daly and Y. Berthier, "Experimental and numerical modelling of the ignition of solid propellant," Tribology International, vol. 82, pp. 330-342, 2015 .

[7] S. Vladescu, A. V. Olver, I. G. Pegg and T. Reddyhoff, "The effects of surface texture in reciprocating contacts - An experimental study," Tribology International, vol. 82, pp. 28-42, 2015.

[8] Y. Fu, A. Batchelor and L. Loh, "Study on fretting wear behavior of laser treated coatings by Xray imaging," Wear, vol. 218, pp. 250-260, 1998.

[9] Y. Fu, A. Batchelor and N. Loh, "Revealing the hidden world of fretting wear processes of surface coatings by X-ray imaging," Surface and Coatings Technology, vol. 107, pp. 133-141, 1998.

[10] M. Chandrasekaran, A. Batchelor and N. Loh , "Direct observation of frictional seizure of mild steel sliding on aluminum by X-ray imaging Part I: Methods," Journal of Material Science, vol. 35, pp. 1589-1596, 2000.

[11] M. Belin, J. Martin, J. SchouI, I. Rasmussen, R. Feidenhans'1, T. Straasø and N. Mikkelsen, "Micro-scale Real-Time Wear Dynamics Investigated by Synchroton Radiation," in Advanced Analytical Methods in Tribology, Springer, 2018.

[12] A. Dorgham, A. Neville, K. Ignatyev, F. Mosselmans and A. Morina, "An in situ synchrotron XAS methodology for surface analysis under high temperature, pressure, and shear," Review of Scientific Instruments, vol. 88, 2017.

[13] F. Zanini, S. Carmignato, E. Savio and S. Affatato, "Uncertainty determination for X-ray computed tomography wear assessment of polyethylene hip joint prostheses," Precision Engineering, vol. 52, pp. 477-483, 2018.

[14] S. Affatato, F. Zanini and S. Carmignato, "Quantification of Wear and Deformation in Different Configurations of Polyethylene Acetabular Cups Using Micro X-ray Computed Tomography," Materials, vol. 10, 2017.

[15] A. Hejjaji, R. Zitoune, L. Crouzeix, S. Le Roux and F. Collombet, "Surface and machining induced damage charaterization of abrasive water jet milled carbon/epoxy composites speciments and their impact on tensile behaviour," Wear, Vols. 376-377, pp. 1356-1364, 2017.

[16] D. Mueth, G. Debregeas, G. Karczmar, P. Eng, S. Nagel and H. Jaeger, "Signatures of granular microstructure in dense shear flows," Nature, vol. 406, pp. 385-389, 2000. 
[17] B. Gould, A. Greco, K. Stadler, E. Vegter and X. Xiao, "Using advanced tomography techniques to investigate the development of White Etching Cracks in a prematurely failed field bearing," vol. 116, pp. 362-370, 2017.

[18] D. Wang, X. Li, X. Wang, D. Zhang and D. Wang, "Dynamic wear evolution and crack propagation behaviors of steel wires during fretting-fatigue," Tribology International, vol. 101, pp. 348-355, 2016.

[19] S. Dhar, H. K. Danielsen, S. Fæster, C. Rasmussen, Y. Zhang and D. Juul Jensen, "Crack formation within a Hadfield manganese steel crossing nose," Wear, Vols. 438-439, 2019.

[20] S. Dhar, H. Danielsen, S. Fæster, C. Rasmussen and D. Juul Jensen, "2D and 3D characterization of rolling contact fatigue cracks in manganese steel wing rails from a crossing," Wear, Vols. 436-437, 2019.

[21] S. Earl, K. Rankin, R. Lewis, L. Smith and W. Rainforth, "Verification of the use of Micro-CT scanning to assess the features of entire squat type defects," Wear, Vols. 438-439, 2019.

[22] H. Proudhon, J. Buffiere and S. Fouvry, "Charaterisation of fretting fatigue damage using synchrotron X-ray micro-tomography," Tribology International, vol. 39, pp. 1106-1113, 2006.

[23] A. de Pannemaecker, J. Buffiere, S. Fouvry and O. Graton, "In situ fretting fatigue crack propagation analysis using synchrotron X-ray radiography," International Journal of Fatigue, vol. 97, pp. 56-69, 2017.

[24] J. Buffiere, H. Proudhon, E. Ferrie, W. Ludwig, E. Maire and P. Cloetens, "Three dimensional imaging of damage in structural materials using high resolution micro-tomography," Nuclear Instruments and Methods in Physics Research, vol. 238, pp. 75-82, 2005.

[25] A. Steuwer, S. Barnes, J. Altenkirch, R. Johnson and P. Withers, "Friction Stir Welding of HSLA-65 Steel: Part II. The Influence of Weld Speed and Tool Material on the Residual Stress Distribution and Tool Wear," Metallurgical and Materials Transactions A, vol. 43A, pp. 23562365, 2012.

[26] P. Cornuault and L. Carpentier, "Tribological mechanisms involved in friction wood welding".

[27] R. Mandard, Y. Desplanques, G. Hauss, J. Fabis, J. Witz and J. Meriaux, "Mechanisms of incursion accommodation during interaction between a vibrating blade and an abradable coating," Wear, Vols. 330-331, pp. 406-418, 2015.

[28] A. Kirk, P. Shipway, W. Sun and C. Bennett, "Debris development in fretting contacts - Debris particles and debris beds," Tribology International, 2019.

[29] A. Kirk, P. Shipway, W. Sun and C. Bennett, "The effect of frequency on both the debris and the development of the tribologically transformed structure during fretting wear of a high strength steel," Wear, Vols. 426-427, pp. 694-703, 2019.

[30] P. Arnaud, S. Fouvry and S. Garcin, "A numerical simulation of fretting wear profile taking account of the evolution of third body layer," Wear, Vols. 376-377, pp. 1475-1488, 2017.

[31] N. Fillot, I. Iordanoff and Y. Berthier, "Modelling third body flows with discrete element method - a tool for understanding wear with adhesive particles," Tribology International, vol. 40, pp. 973-981, 2007. 
[32] T. Yue and M. Wahab, "A Numerical Study on the Effect of Debris Layer on Fretting Wear," Materials, vol. 9, 2016.

[33] W. Li, Y. Huang, B. Fu, Y. Cui and S. Dong, "Fretting damage modelling of liner-bearing interaction by combined finite element-discrete element method.," Tribology international, vol. 61, pp. 19-31, 2013.

[34] J. Hintikka, A. Lehtovaara and A. Mäntylä, "Fretting-induced friction and wear in large flat-onflat contact with quenched and tempered steel," Tribology International, pp. 191-202, 2015.

[35] J. Hintikka, A. Lehtovaara and A. Mäntylä, "Third Particle Ejection Effects on Wear with Quenched and Tempered Steel Fretting Contact," Tribology Transactions, pp. 70-78, 2016.

[36] J. Juoksukangas, V. Nurmi, J. Hintikka, M. Vippola, A. Lehtovaara, A. Mäntylä, J. Vaara and T. Frondelius, "Characterization of cracks formed in large flat-on-flat fretting contact," International Journal of Fatigue, vol. 124, pp. 361-370, 2019.

[37] J. Hintikka, A. Mäntylä, J. Vaara, T. Frondelius and A. Lehtovaara, "Stable and unstable friction in fretting contacts," Tribology International, vol. 131, pp. 73-82.

[38] J. Schindelin, I. Arganda-Carreras, E. Frise, V. Kaynig, M. Longair, T. Pietzsch, S. Preibisch, C. Rueden, S. Saalfeld, B. Schmid, J. Tinevez, D. White, V. Hartenstein, K. Elic, P. Tomancak and A. Cardona, "Fiji: an open-source platform for biological-image analysis," Nature Methods, vol. 9, pp. 676-682, 2012.

[39] J. F. Archard, "Contact and Rubbing of Flat Surfaces," Journal of Applied Physics, vol. 24, pp. 981-988, 1953.

[40] N. Fillot, I. Iordanoff and Y. Berthier, "Simulation of Wear Through Mass Balance in a Dry Contact," Journal of Tribology, vol. 127, pp. 230-237, 2005.

[41] N. Fillot, I. Iordanoff and Y. Berthier, "Wear modelling and the third body concept," Wear, vol. 262, pp. 949-957, 2007.

[42] C. Nielsen, P. Martins and N. Bay, "Modelling of real area of contact between tool and workpiece in metal forming processes including the influence of subsurface deformation," CIRP Annals - Manufacturing Technology, vol. 65, pp. 261-264, 2016.

[43] Y. Waddad, V. Magnier, P. Dufrénoy and G. De Saxcé, "Heat partition and surface temperature in sliding contact systems of rough surfaces," International Journal of Heat and Mass Transfer, vol. 137, pp. 1167-1182, 2019.

[44] S. Yamamoto, T. Liskiewicz, K. Fujimura, K. Tashiro and O. Takai, "Temperature rise of diamond-like carbon during sliding: Consideration of the real contact area," Tribology International, vol. 131, pp. 496-507, 2019.

[45] H. Blok, "The Flash Temperature Concept," Wear, vol. 6, pp. 483-494, 1963.

[46] I. Sung, J. Kim, H. Noh and H. Jang, "Effect of displacement and humidity on contact resistance of copper electrical contacts," Tribology International, vol. 95, pp. 256-261, 2016. 
[47] K. Trinh, A. Tsipenyuk, M. Varenberg, A. Rosenkranz, N. Souza and F. Mücklich, "Wear debris and electrical resistance in textured Sn-coated $\mathrm{Cu}$ contacts subjected to fretting," Wear, Vols. 344-345, pp. 86-98, 2015.

[48] F. Zhang, J. Liu, X. Ding and R. Wang, "Experimental and finite element analyses of contact behaviors between non-transparent rough surfaces," Journal of the Mechanics and Physics of Solids, vol. 126, pp. 87-100, 2019.

[49] P. Stempfle, O. Pantale, T. Djilali, R. Kouitat Njiwa, X. Bourrat and J. Takadoum, "Evaluation of the real contact area in three-body dry friction by micro-thermal analysis," Tribology International, vol. 43, pp. 1794-1805, 2010.

[50] J. Jerier and J. Molinari, "Normal contact between rough surfaces by Discrete Element Method," vol. 47, pp. 1-8, 2011.

[51] M. Ashby, J. Abulawi and H. Kong, "Temperature Maps for Frictional Heating in Dry Sliding," Tribology Transactions, Vols. 577-587, no. 34, 1991.

[52] N. Mitroglou, M. Lorenzi, M. Santini and M. Gavaises, "Application of X-ray micro-computed tomography on high-speed cavitating diesel fuel flows," Experiments in fluids, vol. 57, 2016.

[53] I. Khlifa, A. Vabre, M. Hočevar, K. Fezzaa, S. Fuzier, O. Roussette and O. Coutier-Delgosha, "Fast X-ray imaging of cavitating flows," Experiments in fluids, vol. 58, 2017.

[54] S. Jahangir, E. C. Wagner, R. F. Mudde and C. Poelma, "X-ray computed tomography of cavitating flow in a converging-diverging nozzle," in 10th International Symposium on Cavitation, Baltimore, 2018. 